\title{
Interaction Between Odor Identification Deficit and APOE4 Predicts 6-Year Cognitive Decline in Elderly Individuals
}

\author{
Jonas K. Olofsson ${ }^{1,2,3} \cdot$ Maria Larsson $^{1} \cdot$ Catalina Roa ${ }^{1} \cdot$ Donald A. Wilson ${ }^{2,3} \cdot$ Erika Jonsson Laukka $^{4,5}$
}

Received: 5 April 2019 / Accepted: 12 November 2019 / Published online: 23 November 2019

(c) The Author(s) 2019

\begin{abstract}
Olfactory identification impairment might indicate future cognitive decline in elderly individuals. An unresolved question is to what extent this effect is dependent on the ApoE- $\varepsilon 4$, a genotype associated with risk of Alzheimer's Disease (AD). Given the current concern about reproducibility in empirical research, we assessed this issue in a large sample $(n=1637)$ of older adults (60 - 96 years) from the population-based longitudinal Swedish National Study on Aging and Care in Kungsholmen (SNAC-K). A hierarchical regression analysis was carried out to determine if a low score on an odor identification test, and the presence of ApoE- $\varepsilon 4$, would predict the magnitude of a prospective 6-year change in the Mini-Mental State Examination (MMSE) after controlling for demographic, health-related, and cognitive variables. We found that overall, lower odor identification performance was predictive of cognitive decline, and, as hypothesized, we found that the effect was most pronounced among ApoE- $\varepsilon 4$ carriers. Our results from this high-powered sample suggest that in elderly carriers of the ApoE- $\varepsilon 4$ allele, odor identification impairment provides an indication of future cognitive decline, which has relevance for the prognosis of $\mathrm{AD}$.
\end{abstract}

Keywords Dementia $\cdot$ Alzheimer disease $\cdot$ Olfactory perception $\cdot$ Memory $\cdot$ Aging $\cdot$ Mild cognitive impairment

\section{Introduction}

Old age is often accompanied by a decline in sensory capabilities (Frenck et al. 1998; Murphy et al. 2002; WatabeRudolph et al. 2011). Exaggerated sensory decline trajectories are recognized as early behavioral markers for global cognitive impairment (Albers et al. 2015), which in turn is a well-established pre-clinical manifestation of

Handling Editor: Chandra A. Reynolds

Jonas K. Olofsson

Jonas.olofsson@psychology.su.se

1 Department of Psychology, Stockholm University, Frescati Hagväg 9A, 11419 Stockholm, Sweden

2 Child Study Center, Child and Adolescent Psychiatry, New York University School of Medicine, New York, USA

3 Emotional Brain Institute, Nathan Kline Institute, Orangeburg, USA

4 Aging Research Center, Karolinska Institutet and Stockholm University, Stockholm, Sweden

5 Stockholm Gerontology Research Center, Stockholm, Sweden dementia caused by neurodegenerative disease (Bäckman et al. 2005; Thorvaldsson et al. 2011). In particular, olfactory dysfunction has been suggested to indicate neurodegenerative disease progression in mesolimbic brain areas (Wilson et al. 2007; Devanand et al. 2008). Several research overviews have highlighted the severe olfactory loss observed in patients with Alzheimers' and Pakinsons' disease (Mesholam et al. 1998; Murphy 2019; Rahayel et al. 2012; Welge-Lüssen 2009). Olfactory dysfunction is a more robust indicator than auditory or visual impairment of future mild cognitive impairment (MacDonald et al. 2018). Olfactory dysfunction, whether assessed objectively or by selfreport, is consistently found to predict future dementia and increased mortality risk (Ekström et al., 2017, 2019; Stanciu et al. 2014; Devanand et al. 2000; Devanand et al. 2015a, b). The parallel decline of visual-based cognitive abilities and olfactory capabilities in early-stage dementia might be due to atrophy in regions such as parahippocampal and orbitofrontal cortex that process both olfactory and multisensory information (Devanand et al. 2008; Dintica et al. 2019).

Olfactory dysfunction is common among healthy old individuals, with prevalence ranging between 15 and $70 \%$ depending on sample characteristics and diagnostic criteria 
(Seubert et al. 2017; Murphy et al., 2002; Schubert et al., 2012). As olfactory impairments are common, a key challenge is to localize subgroups where such impairments may be especially informative with regard to future cognitive development. Apolipoprotein E $\varepsilon 4$ carriers may constitute such a subgroup. The ApoE gene is believed to be involved in the regenerative process of neurons, and is expressed in the olfactory bulb and the olfactory epithelium (Nathan et al. 2005; Struble et al. 1999), which are also the areas where the renewal of olfactory cells takes place (Watabe-Rudolph et al. 2011). ApoE has three allelic variations $(\varepsilon 2, \varepsilon 3, \varepsilon 4)$. The $\varepsilon 4$ variant has been linked to olfactory dysfunction in old age in several independent studies (Graves et al. 1999; Olofsson et al. 2009, 2010) and identified as a risk factor for neurodegenerative diseases such as Alzheimer's Disease (AD) (Corder et al. 1993), as well as non-pathological cognitive decline in healthy older adults (Bondi et al. 1995; Henderson et al. 1995). Recent findings suggest that carriers of the ApoE- $\varepsilon 4$ allele may develop olfactory deficits along with episodic memory deficits already in middle-age (Josefsson et al. 2017).

Olofsson et al. (2009) reported that deficits in olfactory identification at baseline could dissociate between normlevel and exacerbated decline in global cognitive performance across a 5-year follow-up period in a sample of 501 cognitively intact older adults from the Betula study conducted in Umeå, Sweden (Nilsson et al. 1997, 2004). Interactive effects were found between odor identification, age, and the genotype ApoE- $\varepsilon 4$, suggesting that elderly carriers of the $\varepsilon 4$ allele that also performed poorly on an odor identification assessment, displayed an overall cognitive decline that was about twice as large as that of participants who exhibited only one, or neither, of these risk factors. These results are consistent with past research reporting that impaired olfactory performance was predictive of impending cognitive decline (Graves et al. 1999; Swan and Carmelli 2002). However, not all reports show an interaction effect between olfactory loss and the $\varepsilon 4$ allele in predicting cognitive decline rates (Dintica et al. 2019; Devanand et al. $2015 \mathrm{a}, \mathrm{b})$. This suggests that more studies are needed on high-powered samples before this interaction is confirmed.

Here, we sought to reproduce the main finding from our prior work (Olofsson et al. 2009) in a much larger sample provided by the SNAC-K project in Stockholm, Sweden. We hypothesized that baseline olfactory performance would predict cognitive decline within a follow-up interval of six years (2001-2007) and that the effect would be primarily observed in ApoE- $\varepsilon 4$ carriers. The methods used in the current study were modelled after our prior work using data from the Betula study in Umeå, Sweden (Olofsson et al. 2009), to maximize the similarity between the studies. A successful replication in a different population-based study cohort would strengthen the generalizability of previous findings, and provide further support for the notion that poor odor identification ability is a reliable marker of future cognitive decline, especially among older carriers of the ApoE- $\varepsilon 4$ allele (Graves et al. 1999; Olofsson et al. 2009).

\section{Method}

\section{Participants}

The data used in the study were derived from the Swedish National Study on Aging and Care in Kungsholmen (SNAC$\mathrm{K})$. SNAC-K is a longitudinal population-based study on aging and health that started in 2001. The original study population comprised of 4590 people randomly selected from the Kungsholmen area in central Stockholm, Sweden. At baseline, 3363 participants were assessed, belonging to 11 pre-specified age cohorts: $60,66,72,78,81,84$, $87,90,93,96$, and 99 years and older. The examination lasted approximately $6 \mathrm{~h}$ and involved a social interview and assessment of physical functioning (performed by nurses); a clinical examination including geriatric, neurological, and psychiatric assessment (performed by physicians); and neuropsychological testing (performed by psychologists). Older participants ( $\geq 78$ years at baseline) are called back for re-assessments every 3 years and younger participants every 6 years. Of 2848 participants who completed the neuropsychological test battery at baseline (Laukka et al. 2013), 2569 provided data on the olfactory test. Reasons for dropout or exclusion of data $(n=279)$ included self-reported anosmia $(n=95,34.1 \%)$, olfactory over-sensitivity $(n=17$, $6.1 \%)$, asthma or allergies $(n=48,17.2 \%)$, tiredness $(n=31$, $11.1 \%)$, refusals $(n=36,12.9 \%)$, or other reasons $(n=52$, $18.6 \%$ ).

To retain a sample of participants with relatively intact cognitive abilities, additional exclusion criteria were applied to exclude participants with a history of schizophrenia or developmental disorder, and those who were diagnosed with dementia (DSM IV criteria), or Parkinsons' disease (CERAD criteria) at the baseline assessment. Furthermore, participants with a MMSE score below 27 at baseline were excluded. Though Olofsson et al.' (2009) original study used an MMSE cut-off score of 25 and above, more recent research has suggested 27 as an optimal cut-off score for screening for Mild Cognitive Impairment (MCI) (Tsai et al. 2016). We decided that the more conservative criterion of MMSE 27 or above would provide the optimal selection of cognitively intact participants, although we also conducted follow-up analyses using the previous cut-off value. The cut-off score of 27 was only applied at baseline and not at follow-up, in order to avoid restricting the range of cognitive decline that provided our outcome measure. Furthermore, participants who developed neurodegenerative disorders 
during the follow-up interval were not excluded or otherwise controlled for in the analysis, as this is a common cause of age-related cognitive decline. After applying all exclusion criteria, there were 2110 participants with complete data at baseline (see Fig. 1 for specifics). At the six-year followup, 1637 participants were re-assessed with the MMSE (see Table 1 for descriptive characteristics of the study sample). Participants who did not return for follow-up testing tended to be older, less educated, have higher cardiovascular disease burden, and score lower on all cognitive tasks at baseline (including the olfactory task; $p \mathrm{~s}<0.05$ ). They were also more likely to have diabetes, be current smokers, or have a history of cerebrovascular disorders at baseline $(p s<0.05)$.
In contrast, there were no differences with regard to sex, $A P O E$ genotype, or history of head trauma ( $p s>0.05)$.

All parts of SNAC-K have been approved by the Karolinska Institutet Ethical committee (dnr 01-114) or the Regional Ethical Review Board (dnrs 04-929/3, Ö 26-2007). The research in SNAC-K was conducted according to the ethical standards stated in the 1964 Declaration of Helsinki. All participants directly provided informed written consent, or in cases where the participants were too severely cognitively impaired, the consent was provided by their next-of-kin.

Fig. 1 Exclusion flowchart

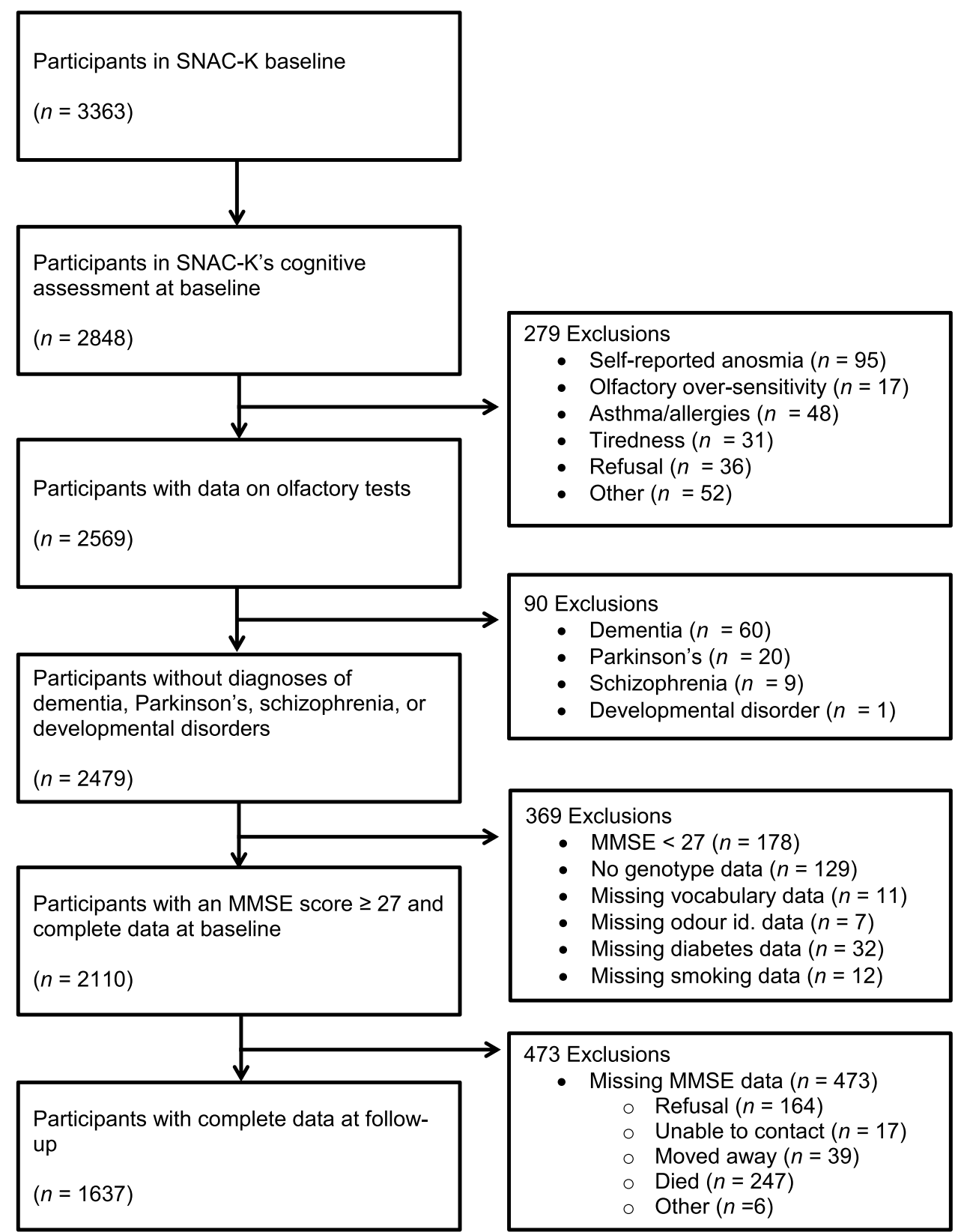


Table 1 Participant characteristics (percentage in parentheses; $n=1637$ )

\begin{tabular}{ll}
\hline Age in years, mean \pm SD & $69.83 \pm 8.66$ \\
Gender, $n$ males/females & $624 / 1013$ \\
Education in years, mean \pm SD & $12.79 \pm 4.19$ \\
ApoE- $\varepsilon 2, n$ & $233(14.2)$ \\
ApoE- $\varepsilon 4, n$ & $488(29.8)$ \\
Diabetes, $n$ & $120(7.3)$ \\
Head injury, $n$ & $224(13.7)$ \\
Cardiovascular disease burden, mean \pm SD & $0.29 \pm 0.61$ \\
Smoking, $n$ & $234(14.3)$ \\
Cerebrovascular disease, $n$ & $105(6.4)$ \\
Odor identification, proportion correct mean \pm SD & $0.77 \pm 0.17$ \\
Vocabulary test, mean \pm SD & $23.73 \pm 4.35$ \\
MMSE at baseline, mean \pm SD & $29.27 \pm 0.83$ \\
MMSE at 6-year follow-up, mean \pm SD & $27.92 \pm 2.82$ \\
\hline
\end{tabular}

\section{Materials and procedure}

\section{Odor identification}

As part of a comprehensive cognitive testing battery, the Sniffin' TOM odor memory test, a standardized assessment with high test-retest reliability, was used to assess odor identification performance (Croy et al. 2015; Hummel et al. 1997). Odor identification was assessed in conjunction with an initial odor recognition memory assessment. Sixteen odors were presented in felt-tip pens during $5 \mathrm{~s}$ odor exposure and $15 \mathrm{~s}$ interstimulus intervals: apple, banana, cinnamon, cloves, coffee, fish, garlic, leather, lemon, liquorice, mushroom, peppermint, petrol, pineapple, rose, and turpentine. Participants were instructed to freely identify the odor; if they did not provide a response, or responded incorrectly, they were presented with four response alternatives (cued identification). In the present context, a correct response under either response format (free or cued) was considered correct (Seubert et al. 2017). Test procedures have been described in more detail elsewhere (Larsson et al. 2016). This procedure is somewhat different from the Betula study, where no olfactory naming or recognition tasks were carried out (Larsson et al. 2004). Furthermore, and as is common in the field of olfactory research, the odors and response alternatives are different across studies. However, we assumed that the two studies would assess the same underlying ability to identify odors.

\section{Cognitive variables}

Global cognitive function The Mini-Mental State Examination (MMSE) was used to measure global cognitive performance. The MMSE is widely used to assess cognitive function and detect cognitive impairment. The MMSE (maximum score $=30$ ) assesses general cognitive performance in various domains, including arithmetic skills, episodic memory, orientation, and language. The test is divided in two sections; the first section requires vocal responses to items assessing orientation, memory, and attention. The second section assesses the ability of the individual to follow verbal and written commands, write down sentences, and draw a replica of a displayed complex polygon (Folstein et al. 1975).

Vocabulary As in our prior work (Olofsson et al. 2009), we statistically controlled for individual differences in vocabulary, as it may influence odor identification performance (Larsson et al. 2004). Thus, part 1 of the Synonyms Reasoning Blocks (SRB:1) (Dureman 1960) test was included. SRB comprises a 30-item multiple-choice vocabulary test to assess verbal knowledge. The participants are instructed to select a synonym for a target word out of five alternatives. The score is calculated by aggregating the number of correct synonyms achieved within the time limit of 7 min. Because the SRB has a similar format to the odor identification test (both assessments involve matching stimuli to a list of written alternatives), it is useful as a non-olfactory control task (Hedner et al. 2010).

\section{Demographic variables}

Various demographic factors influence an individual's general health and aging processes. Differences in lifestyle choices and in the quantity and quality of resources available to an individual promotes disparities in health, accelerating or attenuating age-related deficits (Mobley et al. 2014). We considered several demographic variables including age, gender (male, female), and education (number of years of formal schooling). The information was collected following standard protocols.

\section{Health variables}

Information regarding health variables was collected through self-report, clinical examinations; medication lists, laboratory data, and by accessing the computerised Stockholm inpatient register. The vascular and other health-related variables included diabetes, history of head trauma, smoking (dichotomised into "current smoking" and "no current smoking"), cerebrovascular disease, and cardiovascular disease burden (a composite measure including a history of heart failure, atrial fibrillation, and coronary heart disease). In contrast to Olofsson et al. (2009), information regarding Ear-Nose-and-Throat (ENT) disorders was not collected in SNAC-K. However, considering that ENT disorders had no influence on outcomes in the previous study, we had no reason to believe they would be relevant in this study. 


\section{Genetic variables}

Genotype information for ApoE (rs7412, rs429358) was obtained from peripheral blood samples through standard methods. The genotyping of ApoE was conducted using the Matrix-Assisted Laser Desorption/Ionization Time-OfFlight (MALDI-TOF) analysis on the Sequenom Mass Array platform at the Mutation Analysis Facility, Karolinska Institutet (Darki et al. 2012). The results produced by this procedure were in Hardy Weinberg equilibrium and had a successful genotyping rate of $97 \%$. Participants were grouped as any $\varepsilon 4$ carriers versus no carrier, and any $\varepsilon 2$ carriers versus no carriers. The genotype proportions of the sample at follow-up ( $n=1637)$ were: $\varepsilon 2 / \varepsilon 2,1 \%(n=12) ; \varepsilon 2 / \varepsilon 3,10 \%$ $(n=171) ; \varepsilon 2 / \varepsilon 4,3 \%(n=50) ; \varepsilon 3 / \varepsilon 3,59 \%(n=966) ; \varepsilon 3 / \varepsilon 4$, $24 \%(n=392) ; \varepsilon 4 / \varepsilon 4,3 \%(n=46)$. Following the same protocol as our previous work (Olofsson et al. 2009), the ApoE- $\varepsilon 2$ variant was included in the analysis to control for its reported protective effect against dementia syndromes such as AD (Conejero-Goldberg et al. 2014; Corder et al. 1994).

\section{Statistical analysis}

A hierarchical regression analysis was carried out to determine if odor identification performance was a reliable predictor for MMSE scores at the 6-year follow-up, when MMSE baseline scores, demographic, genetic, and health-related variables were controlled for. An interaction term between odor identification and ApoE- $\varepsilon 4$ was created by mean-centering each score of odor identification and ApoE- $\varepsilon 4$, and multiplying them with each other (Odor id. $\times$ ApoE- $\varepsilon 4)$. Following our previous statistical procedure, the interaction variables were mean-centred for all statistical analyses in order to avoid possible multicollinearity (Olofsson et al. 2009).

The order in which each variable was entered and divided into different blocks for the hierarchical analysis followed our previous method (Olofsson et al. 2009). MMSE performance at the 6-year follow-up was used as the criterion measure, while MMSE performance at baseline was entered in the first block to control for the participants' initial cognitive ability. Thus, the predictors added after the first block effectively constitute predictors of MMSE change. Demographic variables (age, gender, and education) were entered in the second block, as these variables were expected to be associated with health and cognitive performance. This influence needs to be accounted for when estimating the true predictive power of odor identification. Genetic information regarding the ApoE gene (presence of allele $\varepsilon 2$ and $\varepsilon 4$ ) was entered in the third block, since genetic influence is susceptible to interference from social and environmental factors. To account for effects of poor health on cognitive and olfactory performance, health-related variables were entered in the fourth block: diabetes, head injury, cardiovascular disease burden, smoking, and cerebrovascular disease. Odor identification (odor-to-word matching) and a non-olfactory cognitive control assessment of vocabulary (word-to-word matching; SRB:1) were then entered in the fifth block, while the two-way interaction between odor identification and ApoE- $\varepsilon 4$ was entered in the final block.

\section{Results}

The intercorrelations among all variables were calculated using Pearson correlation coefficients (see Table 2). Although strong correlations among the predictor variables would suggest a possible multicollinearity issue, the observed correlations here were weak to moderate, ranging from $r=-0.31, p<0.001$ to $r=0.41, p<0.001$. Most predictor variables were correlated with MMSE at follow-up with the exception of gender, ApoE- $\varepsilon 2$, occurrence of head injury, and current smoking. In addition, data screening indicated no multicollinearity among any of the predictor variables, with all tolerance values being above 0.10 and variance inflation factors (VIFs) below 10. The observed significant correlations among odor identification, ApoE- $\varepsilon 4$, and MMSE at follow-up motivated further examination of the data through hierarchical regression analysis to determine if these associations were unique and independent from possible mediating effects of the other variables.

The results from the hierarchical regression analysis are presented in Table 3 and indicate that after statistical control of baseline MMSE performance, all following blocks included in the regression analysis significantly accounted for a unique and significant proportion of the variance in cognitive performance (MMSE at follow-up). MMSE performance at baseline initially accounted for $8.5 \%$ of the variance in cognitive performance $(p<0.001)$, and after the demographic block was included the model as a whole accounted for $19.7 \%$. This indicates that demographic variables explained an additional $11.2 \%$ of the variance in the criterion measure $(p<0.001)$, which was the largest contribution to the model of all the different blocks. The following block containing genetic variables accounted for an additional $0.9 \%$ of the variation $(p<0.001$. However, of the two variables, only ApoE- $\varepsilon 4$ contributed reliably, suggesting that the presence of an $\varepsilon 4$ allele had a significant negative influence on MMSE change. Health variables accounted for another $2.4 \%$ of the variance in cognitive performance $(p<0.001)$, specifically the smoking and cerebrovascular disease variables.

The block consisting of performance in sensory/cognitive tests accounted for $1.4 \%$ of the variance $(p<0.001)$, with both participants' performance in odor identification and 
Table 2 Intercorrelations among variables

\begin{tabular}{|c|c|c|c|c|c|c|c|c|c|c|c|c|c|c|}
\hline Variable & 1 & 2 & 3 & 4 & 5 & 6 & 7 & 8 & 9 & 10 & 11 & 12 & 13 & 14 \\
\hline 1. Age & - & & & & & & & & & & & & & \\
\hline 2. Gender & 0.10 & - & & & & & & & & & & & & \\
\hline 3. Education & -0.31 & -0.09 & - & & & & & & & & & & & \\
\hline 4. ApoE- $\varepsilon 2$ & 0.00 & 0.01 & 0.00 & - & & & & & & & & & & \\
\hline 5. ApoE- $\varepsilon 4$ & 0.05 & 0.01 & -0.01 & 0.07 & - & & & & & & & & & \\
\hline 6. Diabetes & 0.04 & -0.12 & -0.05 & -0.01 & 0.04 & - & & & & & & & & \\
\hline 7. Head injury & -0.07 & -0.11 & 0.03 & -0.02 & 0.01 & -0.02 & - & & & & & & & \\
\hline 8. Cardiovascular disease burden & 0.28 & -0.09 & -0.09 & -0.04 & -0.03 & 0.15 & 0.05 & - & & & & & & \\
\hline 9. Smoking & -0.14 & 0.01 & 0.03 & -0.02 & 0.01 & -0.03 & 0.03 & -0.07 & - & & & & & \\
\hline 10. Cerebrovascular disease & 0.17 & -0.02 & -0.08 & -0.04 & -0.00 & 0.01 & -0.01 & 0.13 & -0.01 & - & & & & \\
\hline 11. Odor identification & -0.22 & 0.10 & 0.15 & 0.02 & 0.04 & -0.07 & -0.04 & -0.12 & 0.03 & -0.07 & - & & & \\
\hline 12. Vocabulary & -0.33 & 0.00 & 0.41 & 0.00 & -0.02 & -0.04 & 0.03 & -0.08 & 0.05 & -0.08 & 0.18 & - & & \\
\hline 13. MMSE at baseline & -0.29 & 0.00 & 0.22 & 0.01 & -0.04 & -0.04 & -0.04 & -0.13 & 0.05 & -0.08 & 0.17 & 0.17 & - & \\
\hline 14. MMSE at 6-year follow-up & -0.38 & 0.02 & 0.26 & 0.01 & 0.07 & -0.06 & 0.01 & -0.13 & 0.01 & -0.21 & 0.22 & 0.22 & 0.29 & - \\
\hline
\end{tabular}

Correlations in bold are significant, $p<.05$

Table 3 Hierarchical regression analysis for predicting cognitive performance (MMSE score) at follow-up $(n=1637)$

\begin{tabular}{lllll}
\hline & $R 2 \Delta$ & $R^{2}$ & $\beta$ & $p$ \\
\hline 1. MMSE at baseline & 0.085 & 0.085 & 0.292 & $0.000^{* * *}$ \\
2. Demographic & 0.112 & 0.197 & & \\
Age & & & -0.289 & $0.000^{* * *}$ \\
Gender $(1=\mathrm{m}, 2=\mathrm{f})$ & & & 0.041 & 0.068 \\
Education & & & 0.137 & $0.000^{* * *}$ \\
3. Genetic & 0.009 & 0.206 & & \\
ApoE- $\varepsilon$ 4 & & & -0.092 & $0.000^{* * *}$ \\
ApoE- $\varepsilon$ 2 & & & 0.005 & 0.806 \\
4. Health & 0.024 & 0.229 & & \\
Diabetes & & & -0.037 & 0.093 \\
Head injury & & & -0.009 & 0.684 \\
Cardiovascular disease & & & 0.009 & 0.711 \\
$\quad$ burden & & & & \\
Smoking & & & -0.050 & $0.023^{*}$ \\
Cerebrovascular disease & & & -0.143 & $0.000^{* * *}$ \\
5. Sensory/cognitive tests & 0.014 & 0.243 & & \\
$\quad$ Odor identification & & & 0.056 & $0.016^{*}$ \\
Vocabulary test & & & 0.115 & $0.000^{* * *}$ \\
6. Two-way interaction & 0.003 & 0.246 & & \\
Odor id. $\times$ ApoE- $\varepsilon 4$ & & & 0.054 & $0.013^{*}$ \\
\hline
\end{tabular}

MMSE Mini Mental State Examination

$* p<0.05 ; * * p<0.01 ; * * p<0.001$

in the vocabulary test exerting a significant positive influence on cognitive ability at follow-up. This indicates that better odor identification performance and vocabulary test performance are associated with less changes in cognitive ability, even after controlling for the effects of MMSE at

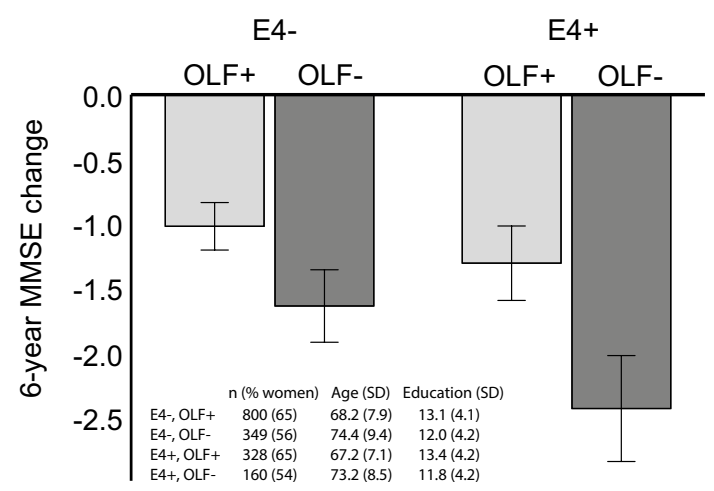

Fig. 2 Mean change in MMSE scores $( \pm 2 S D)$ from baseline to follow-up in $\varepsilon 4$ carriers (E4+) and non-carriers (E4-), divided into groups of odor identification scores below median (OLF-, light grey bars) or above median (OLF+, dark grey bars). Insert shows descriptive demographics (n, age, and education) in these four groups

baseline, demographic, genetic, and health variables. The final block containing the two-way interaction between odor identification and ApoE- $\varepsilon 4$ accounted for $0.3 \%$ of the variance $(p<0.05)$, indicating that the interaction between odor identification performance and ApoE- $\varepsilon 4$ significantly influenced cognitive change.

Figure 2 illustrates the interaction between odor identification and ApoE- $\varepsilon 4$, based on a median split of the odor identification scores which was applied in order to classify participants. Figure 2 uses data unadjusted for demographic differences between the groups, which are instead shown in a table insert. Among participants with below-median odor identification score, ApoE- $\varepsilon 4$ carriers show a larger decrease in MMSE score. In participants with above-median odor identification score, the ApoE- $\varepsilon 4$ effect is less notable. 
Note that in Fig. 2, demographic characteristics (which were accounted for in the statistical analysis) differ somewhat between groups of high and low odor identification performance, but not between ApoE- $\varepsilon 4$ carriers and non-carriers. To strengthen the validity of this main result, we conducted two follow-up analyses. First, we assessed whether the interaction effect would be retained if we replaced odor identification with vocabulary in the interaction with ApoE- $\varepsilon 4$. The regression was otherwise identical to that presented in Table III. The results showed that the vocabulary $\times$ ApoE- $\varepsilon 4$ interaction was not significant $(t=1.580 ; p=0.114)$, which further strengthened our conclusion that the observed interaction effect was olfactory-specific. Second, we conducted a follow-up analysis to assess whether the main result would be retained when using the more liberal inclusion criterion of MMSE 25 or above. Results from this slightly larger sample $(\mathrm{n}=1689)$ were highly similar to those presented in Table 3; the interaction of odor identification $\times$ ApoE- $\varepsilon 4$ was still significant $(\mathrm{p}=0.014)$, supporting our main result.

\section{Discussion}

As olfactory deficits emerge as a potential biomarker for cognitive impairment and dementia (Murphy 2019), highpowered studies are needed to determine subgroups where this relationship is especially strong. The present study uses a combination of a longitudinal study design, and assessments of cognition, olfaction and genetics, to enable conclusions regarding relationship among olfaction, ApoE, and 6-year cognitive decline. In line with previous research (Graves et al. 1999; Larsson et al. 2016; Olofsson et al. 2009), this investigation finds that the combination of poor olfactory identification and the ApoE- $\varepsilon 4$ genotype is predictive of a future decline in cognitive performance, also after controlling for baseline cognitive function, demographic, genetic, and health factors. However, in line with other published reports (Devanand et al. 2015a, b; Schubert et al. 2008; Wilson et al. 2007), the present study also found that poor baseline olfactory identification alone predicted future cognitive decline (i.e. the effect of olfactory impairment on future cognitive decline is also present, albeit less pronounced, in ApoE- $\varepsilon 4$ non-carriers). These results contribute to the growing body of research suggesting that olfactory identification deficits are useful in predicting cognitive decline. As the neural processes underlying successful odor identification are becoming more well established, in both rats and humans, this might provide an opportunity for cross-species translation of findings (Olofsson et al. 2019; Zhou et al. 2019).

The interaction effect between poor odor identification ability and ApoE- $\varepsilon 4$ in predicting future cognitive decline fits well with what is known about regional accumulation of $\mathrm{AD}$ neuropathology in preclinical stages. According to the Braak staging model of $\mathrm{AD}$, amyloid and tau pathologies are initiated in the entorhinal cortex and surrounding areas of the antero-medial temporal lobes, where olfactory processing takes place (Braak and Braak 1995; Braak et al. 1993). At this stage, such focal pathology is yet to affect global cognitive functions. Odor identification assessments might provide an index of the severity of a neuropathological load specifically in mediotemporal regions, which are affected in preclinical stages of AD (Devanand et al. 2008; Dintica et al. 2019; Hagemeier et al. 2016; Vassilaki et al. 2017). Why is the relationship between current olfactory impairments and future cognitive decline weaker in ApoE- $\varepsilon 4$ non-carriers? This might be a result of different patterns of cortical atrophy, as those who develop AD without ApoE- $\varepsilon 4$ display cortical atrophy predominantly in fronto-parietal cortex, which is accompanied by executive function deficits, whereas AD patients with ApoE- $\varepsilon 4$ display cortical atrophy predominantly in the mediotemporal cortex, which is accompanied by memory deficits (Wolk et al. 2010). As fronto-parietal regions are less critical for olfaction, cognitive functions may thus decline in some non-carriers, largely independently of their olfactory abilities. However, it should be noted that other biological pathways are also possible to explain the effects of ApoE- $\varepsilon 4$. For example, mice implanted with human ApoE- $\varepsilon 4$ show an enhanced response to odors in the olfactory bulb and piriform cortex, as well as a lack of olfactory habituation across multiple stimulations (East et al. 2018). This finding suggests a neuronal inhibition failure, perhaps explained by deficits in the exosomal pathways of neurons (Peng et al. 2017). Given these observations in mice, which lack typical AD neuropathology, it is possible that olfactory impairments in human ApoE- $\varepsilon 4$ carriers may be caused also by non-pathological mechanisms such as exosomal changes.

Our current focus on replicating our prior findings is in line with the increasing focus on reproducible research. Unfortunately, while reproducibility is considered a cornerstone of empirical science, a large body of work suggests many empirical research findings are exaggerated or false (Ioannidis 2005; Open Science Collaboration 2015; Prinz et al. 2011). It has been estimated that a successful replication of a prior positive finding increases the likelihood of the finding being true from 50 to $95 \%$ (Dreber et al., 2015). Indeed, our successful replication of the previously published interaction effect (Olofsson et al. 2009), using a sample three times larger, suggests the effect is robust. However, because of the small effect size it might only be observed in high-powered samples. Our observed interaction between olfactory impairment and ApoE- $\varepsilon 4$ was not observed in all prior studies (Devanand et al. 2015a, b; Dintica et al. 2019). We suggest that this discrepancy may be due to the fact that $\varepsilon 4$ is rare, its effects on olfaction are overall of small size, 
and its relationship with $\mathrm{AD}$ is especially strong in individuals with European and Asian ancestry, and weaker in individuals with African ancestry (Farrer et al. 1997; Rajabli et al. 2018). While the latter finding might be due to a variety of mechanisms, recent results indicate an important role of ancestry-specific genetic effects near the ApoE region in the genome, rather than non-genetic cultural or environmental factors (Rajabli et al. 2018). We speculate that the studies conducted at the Rush Memory and Aging Project (Dintica et al. 2019), Washington Heights/Inwood Columbia Aging Project (Devanand et al. 2015a, b), or the Swedish Adoption/ Twin Study of Aging (Finkel et al. 2011), including samples that are different in demographics and size compared the Swedish Betula and SNAC-K studies, would be less likely to observe an interaction between olfactory impairment and ApoE- $\varepsilon 4$, whereas the present study, using a large sample of Swedish participants, might be more likely to observe an interaction. We recommend that future empirical work on olfaction and cognition/AD outcomes report interactions with ApoE, even when negative, so that meta-analyses may answer such questions more definitively.

The present work highlights the role of sensory deficits as a complement to cognitive decline as a means of early-stage detection of $\mathrm{AD}$ and other age-related disorders (Bacon et al. 1998). Olfaction might provide the best sensory target for AD prognosis, although sensory markers focusing on the visual and auditory systems are also viable (Murphy 2019). A critical issue for future research is to compare different olfactory tests in their prediction of cognitive decline. Different olfactory abilities may diminish at different rates with age (Larsson et al. 2016). Meta-analytic evidence suggests that "cognitive" olfactory functions (identification, recognition) may show larger impairments in Alzheimers disease compared to "sensory" olfactory functions (detection, discrimination) (Rahayel et al. 2012). Importantly, neuropathology can manifest in brain regions involved in olfactory functions without affecting other sensory areas (Van Hoesen and Solodkin 1994). Given that current olfactory assessments are not optimized for the detection of specific conditions, the development of such assessments is likely to provide stronger effects and better diagnostic utility.

Among the possible limitations of this study is the use of MMSE to assess cognitive ability. Though MMSE is widely used, the MMSE has been criticized for its psychometric properties (Mitchell 2013; Proust-Lima et al. 2007; Tombaugh and McIntyre 1992). Despite its limitations, MMSE remains a valuable tool for assessing overall cognitive function (Han et al. 2000) and the use of MMSE change scores in the present work was justified by our aim to replicate the methods used in our previous work (Olofsson et al. 2009). In future studies, we will compare decline trajectories in multiple cognitive domains and across multiple time points (Josefsson et al. 2017). Such data will allow us to better account for measurement error and establish decline trajectories (Singer and Willett 2003). Another limitation of our work is that $23 \%$ of participants did not return for the follow-up assessment, mostly because poor health and incident death was prevalent in this sample of older adults. We analysed differences between those who returned and those who did not return, and found the latter group to be older, of poorer health and performing more poorly on cognitive tests (including the olfactory assessment) at baseline. However, ApoE status did not affect risk of dropout, and as olfactory dysfunction was only linked to dropout as part of an overall pattern of poor cognitive performance, it seems unlikely that our interaction effect was somehow driven by dropout. Finally, we note that odor identification was somewhat less effective than vocabulary in predicting cognitive impairment. We speculate that this advantage of vocabulary over olfaction was due to two reasons. First, the olfactory test was brief, including 16-items compared to the 30-item vocabulary test, and adding more items to the odor identification test would likely lead to higher reliability and predictive accuracy (Freiherr et al. 2012). Second, vocabulary is often used as a proxy for lifestyle factors that enhances "cognitive reserve" capacity and prevents cognitive decline (Soldan et al. 2017). While it is thus not surprising that vocabulary effectively predicts cognitive decline, future studies should include more in-depth olfactory assessments in order to optimize its role as a complement to other cognitive assessments.

To conclude, the present findings replicate and extend previous work by showing that both odor identification performance at baseline, and the interaction of odor identification performance and ApoE- $\varepsilon 4$, can be used to predict the magnitude of future cognitive decline. These findings are promising as they have clinical implications for the efforts to distinguish between normative and harmful cognitive decline trajectories in old age, and for the early identification of individuals at risk of dementia conversion.

Acknowledgements Open access funding provided by Stockholm University. We thank the participants as well as all staff involved in the data collection and management of the SNAC-K study. SNAC-K is financially supported by the Swedish Ministry of Health and Social Affairs, the participating County Councils and Municipalities, and the Swedish Research Council. This work was further funded by grants from the Swedish Research Council (EL: 2017-01759), the Swedish Foundation for Humanities and Social Sciences (ML: M14-0375:1), Knut and Alice Wallenberg Foundation (JO: KAW 2016:0229).

\section{Compliance with ethical standards}

Conflict of interest Jonas K. Olofsson, Maria Larsson, Catalina Roa, Donald A. Wilson and Erika Jonsson Laukka declare that they have no conflict of interest.

Human and Animal Rights and Informed Consent All parts of SNAC$\mathrm{K}$ have been approved by the Karolinska Institutet Ethical committee 
(dnr 01-114) or the Regional Ethical Review Board (dnrs 04-929/3, Ö 26-2007). The research in SNAC-K was conducted according to the ethical standards stated in the 1964 Declaration of Helsinki. All participants directly provided informed written consent, or in cases where the participants were too severely cognitively impaired, the consent was provided by their next-of-kin.

Open Access This article is distributed under the terms of the Creative Commons Attribution 4.0 International License (http://creativeco mmons.org/licenses/by/4.0/), which permits unrestricted use, distribution, and reproduction in any medium, provided you give appropriate credit to the original author(s) and the source, provide a link to the Creative Commons license, and indicate if changes were made.

\section{References}

Albers MW, Gilmore GC, Kaye J, Murphy C, Wingfield A, Bennett DA et al (2015) At the interface of sensory and motor dysfunctions and Alzheimer's disease. Alzheimers Dement 11(1):70-98. https ://doi.org/10.1016/j.jalz.2014.04.514

Bäckman L, Jones S, Berger A-K, Laukka EJ, Small BJ (2005) Cognitive impairment in preclinical Alzheimer's disease: a meta-analysis. Neuropsychology 19(4):520-531. https://doi. org/10.1037/0894-4105.19.4.520

Bacon AW, Bondi MW, Salmon DP, Murphy C (1998) Very early changes in olfactory functioning due to Alzheimer's disease and the role of apolipoprotein E in olfaction. Ann N Y Acad Sci 855:723-731

Bondi MW, Salmon DP, Monsch AU, Galasko D, Butters N, Klauber MR et al (1995) Episodic memory changes are associated with the APOE-epsilon 4 allele in nondemented older adults. Neurology 45(12):2203-2206

Braak H, Braak E (1995) Staging of Alzheimer's disease-related neurofibrillary changes. Neurobiol Aging 16(3):271-278

Braak H, Braak E, Bohl J (1993) Staging of Alzheimer-related cortical destruction. Eur Neurol 33(6):403-408. https://doi. org/10.1159/000116984

Conejero-Goldberg C, Gomar JJ, Bobes-Bascaran T, Hyde TM, Kleinman JE, Herman MM et al (2014) APOE2 enhances neuroprotection against Alzheimer's disease through multiple molecular mechanisms. Mol Psychiatry 19(11):1243-1250. https://doi. org/10.1038/mp.2013.194

Corder EH, Saunders AM, Strittmatter WJ, Schmechel DE, Gaskell PC, Small GW et al (1993) Gene dose of apolipoprotein E type 4 allele and the risk of Alzheimer's disease in late onset families. Science 261(5123):921-923

Corder EH, Saunders AM, Risch NJ, Strittmatter WJ, Schmechel DE, Gaskell PC et al (1994) Protective effect of apolipoprotein E type 2 allele for late onset Alzheimer disease. Nat Genet 7(2):180-184. https://doi.org/10.1038/ng0694-180

Croy I, Zehner C, Larsson M, Zucco GM, Hummel T (2015) Testretest reliability and validity of the Sniffin' TOM odor memory test. Chem Senses 40(3):173-179. https://doi.org/10.1093/chems e/bju069

Darki F, Peyrard-Janvid M, Matsson H, Kere J, Klingberg T (2012) Three dyslexia susceptibility genes, DYX1C1, DCDC2, and KIAA0319, affect temporo-parietal white matter structure. Biol Psychiatry 72(8):671-676. https://doi.org/10.1016/j.biops ych.2012.05.008

Devanand DP, Michaels-Marston KS, Liu X, Pelton GH, Padilla M, Marder K et al (2000) Olfactory deficits in patients with mild cognitive impairment predict Alzheimer's disease at follow-up.
Am J Psychiatry 157(9):1399-1405. https://doi.org/10.1176/appi. ajp.157.9.1399

Devanand DP, Liu X, Tabert MH, Pradhaban G, Cuasay K, Bell K et al (2008) Combining early markers strongly predicts conversion from mild cognitive impairment to Alzheimer's disease. Biol Psychiatry 64(10):871-879. https://doi.org/10.1016/j.biops ych.2008.06.020

Devanand DP, Lee S, Manly J, Andrews H, Schupf N, Doty RL et al (2015a) Olfactory deficits predict cognitive decline and Alzheimer dementia in an urban community. Neurology 84(2):182-189. https ://doi.org/10.1212/WNL.0000000000001132

Devanand DP, Lee S, Manly J, Andrews H, Schupf N, Masurkar A et al (2015b) Olfactory identification deficits and increased mortality in the community. Ann Neurol 78(3):401-411. https://doi. org/10.1002/ana.24447

Dintica CS, Marseglia A, Rizzuto D, Wang R, Seubert J, Arfanakis K et al (2019) Impaired olfaction is associated with cognitive decline and neurodegeneration in the brain. Neurology 10000:1000. https ://doi.org/10.1212/WNL.0000000000006919

Dreber A, Pfeiffer T, Almenberg J, Isaksson S, Wilson B, Chen Y et al (2015) Using prediction markets to estimate the reproducibility of scientific research. Proc Natl Acad Sci USA 112(50):1534315347. https://doi.org/10.1073/pnas. 1516179112

Dureman I (1960) SRB: 1. Psykologiförlaget, Stockholm

East BS, Fleming G, Peng K, Olofsson JK, Levy E, Mathews PM, Wilson DA (2018) Human apolipoprotein E genotype differentially affects olfactory behavior and sensory physiology in mice. Neuroscience 380:103-110. https://doi.org/10.1016/j.neuroscien ce.2018.04.009

Ekström I, Sjölund S, Nordin S, Nordin Adolfsson A, Adolfsson R, Nilsson L-G et al (2017) Smell loss predicts mortality risk regardless of dementia conversion. J Am Geriatr Soc 65(6):1238-1243. https://doi.org/10.1111/jgs.14770

Ekström I, Josefsson M, Larsson M, Rönnlund M, Nordin S, Olofsson JK (2019) Subjective olfactory loss in older adults concurs with long-term odor identification decline. Chem Senses 44(2):105112. https://doi.org/10.1093/chemse/bjy079

Farrer LA, Cupples LA, Haines JL, Hyman B, Kukull WA, Mayeux $R$ et al (1997) Effects of age, sex, and ethnicity on the association between apolipoprotein E genotype and Alzheimer disease. A meta-analysis. APOE and Alzheimer Disease Meta Analysis Consortium. JAMA 278(16):1349-1356

Finkel D, Reynolds CA, Larsson M, Gatz M, Pedersen NL (2011) Both odor identification and ApoE- $\varepsilon 4$ contribute to normative cognitive aging. Psychol Aging 26(4):872-883. https://doi.org/10.1037/ a0023371

Folstein MF, Folstein SE, McHugh PR (1975) "Mini-mental state". A practical method for grading the cognitive state of patients for the clinician. J Psychiatr Res 12(3):189-198

Freiherr J, Gordon AR, Alden EC, Ponting AL, Hernandez MF, Boesveldt S, Lundström JN (2012) The 40-item Monell Extended Sniffin' Sticks Identification Test (MONEX-40). J Neurosci Methods 205(1):10-16. https://doi.org/10.1016/j.jneumeth.2011.12.004

Frenck RW, Blackburn EH, Shannon KM (1998) The rate of telomere sequence loss in human leukocytes varies with age. Proc Natl Acad Sci USA 95(10):5607-5610

Graves AB, Bowen JD, Rajaram L, McCormick WC, McCurry SM, Schellenberg GD, Larson EB (1999) Impaired olfaction as a marker for cognitive decline: interaction with apolipoprotein $\mathrm{E}$ epsilon4 status. Neurology 53(7):1480-1487

Hagemeier J, Woodward MR, Rafique UA, Amrutkar CV, Bergsland N, Dwyer MG et al (2016) Odor identification deficit in mild cognitive impairment and Alzheimer's disease is associated with hippocampal and deep gray matter atrophy. Psychiatry Res Neuroimaging 255:87-93. https://doi.org/10.1016/j.pscychresn s.2016.08.003 
Han L, Cole M, Bellavance F, McCusker J, Primeau F (2000) Tracking cognitive decline in Alzheimer's disease using the minimental state examination: a meta-analysis. Int Psychogeriatr 12(2):231-247

Hedner M, Nilsson L, Olofsson JK, Bergman O, Eriksson E, Nyberg L, Larsson M (2010) Age-related olfactory decline is associated with the BDNF val66met polymorphism: evidence from a populationbased study. Front Aging Neurosci. https://doi.org/10.3389/fnagi .2010 .00024

Henderson AS, Easteal S, Jorm AF, Mackinnon AJ, Korten AE, Christensen $\mathrm{H}$ et al (1995) Apolipoprotein E allele epsilon 4, dementia, and cognitive decline in a population sample. Lancet (London, Engl) 346(8987):1387-1390

Hummel T, Sekinger B, Wolf SR, Pauli E, Kobal G (1997) "Sniffin" sticks': olfactory performance assessed by the combined testing of odor identification, odor discrimination and olfactory threshold. Chem Senses 22(1):39-52

Ioannidis JPA (2005) Why most published research findings are false. PLoS Med 2(8):e124. https://doi.org/10.1371/journal.pmed.00201 24

Josefsson M, Larsson M, Nordin S, Adolfsson R, Olofsson J (2017) APOE- $\varepsilon 4$ effects on longitudinal decline in olfactory and nonolfactory cognitive abilities in middle-aged and old adults. Sci Rep 7(1):1286. https://doi.org/10.1038/s41598-017-01508-7

Larsson M, Nilsson L-G, Olofsson JK, Nordin S (2004) Demographic and cognitive predictors of cued odor identification: evidence from a population-based study. Chem Senses 29(6):547-554. https://doi.org/10.1093/chemse/bjh059

Larsson M, Hedner M, Papenberg G, Seubert J, Bäckman L, Laukka EJ (2016) Olfactory memory in the old and very old: relations to episodic and semantic memory and APOE genotype. Neurobiol Aging 38:118-126. https://doi.org/10.1016/j.neurobiola ging.2015.11.012

Laukka EJ, Lövdén M, Herlitz A, Karlsson S, Ferencz B, Pantzar A et al (2013) Genetic effects on old-age cognitive functioning: a population-based study. Psychol Aging 28(1):262-274. https:// doi.org/10.1037/a0030829

MacDonald SWS, Keller CJC, Brewster PWH, Dixon RA (2018) Contrasting olfaction, vision, and audition as predictors of cognitive change and impairment in non-demented older adults. Neuropsychology 32(4):450-460. https://doi.org/10.1037/neu00 00439

Mesholam RI, Moberg PJ, Mahr RN, Doty RL (1998) Olfaction in neurodegenerative disease: a meta-analysis of olfactory functioning in Alzheimer's and Parkinson's diseases. Arch Neurol 55(1):84-90

Mitchell AJ (2013). The Mini-Mental State Examination (MMSE): an update on its diagnostic validity for cognitive disorders. In: Larner $\mathrm{AJ}$ (ed) Cognitive screening instruments: a practical approach. Springer, London, pp 15-46. DOI: 10.1007/978-1-4471-2452-8_2.

Mobley AS, Rodriguez-Gil DJ, Imamura F, Greer CA (2014) Aging in the olfactory system. Trends Neurosci 37(2):77-84. https://doi. org/10.1016/j.tins.2013.11.004

Murphy C (2019) Olfactory and other sensory impairments in Alzheimer disease. Nat Rev Neurol 15(1):11-24. https://doi.org/10.1038/ s41582-018-0097-5

Murphy C, Schubert CR, Cruickshanks KJ, Klein BEK, Klein R, Nondahl DM (2002) Prevalence of olfactory impairment in older adults. JAMA 288(18):2307-2312

Nathan BP, Nisar R, Short J, Randall S, Grissom E, Griffin G et al (2005) Delayed olfactory nerve regeneration in ApoE-deficient mice. Brain Res 1041(1):87-94. https://doi.org/10.1016/j.brain res.2005.02.011

Nilsson L-G, Bäckman L, Erngrund K, Nyberg L, Adolfsson R, Bucht $G$ et al (1997) The betula prospective cohort study: Memory, health, and aging. Aging Neuropsychol Cognit 4(1):1-32. https ://doi.org/10.1080/13825589708256633

Nilsson L-G, Adolfsson R, Bäckman L, de Frias CM, Molander B, Nyberg L (2004) Betula: a prospective cohort study on memory, health and aging. Aging Neuropsychol Cognit 11(2-3):134-148. https://doi.org/10.1080/13825580490511026

Olofsson JK, Rönnlund M, Nordin S, Nyberg L, Nilsson L-G, Larsson M (2009) Odor identification deficit as a predictor of five-year global cognitive change: interactive effects with age and ApoEepsilon4. Behav Genet 39(5):496-503. https://doi.org/10.1007/ s10519-009-9289-5

Olofsson JK, Nordin S, Wiens S, Hedner M, Nilsson L-G, Larsson M (2010) Odor identification impairment in carriers of ApoEvarepsilon 4 is independent of clinical dementia. Neurobiol Aging 31(4):567-577. https://doi.org/10.1016/j.neurobiola ging.2008.05.019

Olofsson JK, Zhou G, East BS, Zelano C, Wilson DA (2019) Odor identification in rats: behavioral and electrophysiological evidence of learned olfactory-auditory associations. ENeuro. https://doi. org/10.1523/ENEURO.0102-19.2019

Open Science Collaboration (2015) Estimating the reproducibility of psychological science. Science. https://doi.org/10.1126/scien ce.aac4716

Peng KY, Mathews PM, Levy E, Wilson DA (2017) Apolipoprotein E4 causes early olfactory network abnormalities and short-term olfactory memory impairments. Neuroscience 343:364-371. https ://doi.org/10.1016/j.neuroscience.2016.12.004

Prinz F, Schlange T, Asadullah K (2011) Believe it or not: how much can we rely on published data on potential drug targets? Nat Rev Drug Discov 10(9):712. https://doi.org/10.1038/nrd3439-c1

Proust-Lima C, Amieva H, Dartigues J-F, Jacqmin-Gadda H (2007) Sensitivity of four psychometric tests to measure cognitive changes in brain aging-population-based studies. Am J Epidemiol 165(3):344-350. https://doi.org/10.1093/aje/kwk017

Rahayel S, Frasnelli J, Joubert S (2012) The effect of Alzheimer's disease and Parkinson's disease on olfaction: a meta-analysis. Behav Brain Res 231(1):60-74. https://doi.org/10.1016/j. bbr.2012.02.047

Rajabli F, Feliciano BE, Celis K, Hamilton-Nelson KL, Whitehead PL, Adams LD et al (2018) Ancestral origin of ApoE 84 Alzheimer disease risk in Puerto Rican and African American populations. PLoS Genet 14(12):e1007791. https://doi.org/10.1371/ journal.pgen.1007791

Schubert CR, Carmichael LL, Murphy C, Klein BEK, Klein R, Cruickshanks KJ (2008) Olfaction and the 5-year incidence of cognitive impairment in an epidemiological study of older adults. J Am Geriatr Soc 56(8):1517-1521. https://doi.org/10. 1111/j.1532-5415.2008.01826.x

Schubert CR, Cruickshanks KJ, Fischer ME, Huang G-H, Klein BEK, Klein R et al (2012) Olfactory impairment in an adult population: the Beaver Dam Offspring Study. Chem Senses 37(4):325-334. https://doi.org/10.1093/chemse/bjr102

Seubert J, Laukka EJ, Rizzuto D, Hummel T, Fratiglioni L, Bäckman L, Larsson M (2017) Prevalence and correlates of olfactory dysfunction in old age: a population-based study. J Gerontol Ser A Biol Sci Med Sci 72(8):1072-1079. https://doi.org/10.1093/ gerona/glx054

Singer JD, Willett JB (2003) Applied longitudinal data analysis: modeling change and event occurrence. Oxford University Press, Oxford

Soldan A, Pettigrew C, Cai Q, Wang J, Wang M-C, Moghekar A et al (2017) Cognitive reserve and long-term change in cognition in aging and preclinical Alzheimer's disease. Neurobiol Aging 60:164-172. https://doi.org/10.1016/j.neurobiola ging.2017.09.002 
Stanciu I, Larsson M, Nordin S, Adolfsson R, Nilsson L-G, Olofsson JK (2014) Olfactory impairment and subjective olfactory complaints independently predict conversion to dementia: a longitudinal, population-based study. J Int Neuropsychol Soc 20(2):209-217. https://doi.org/10.1017/S1355617713001409

Struble RG, Short J, Ghobrial M, Nathan BP (1999) Apolipoprotein E immunoreactivity in human and mouse olfactory bulb. Neurosci Lett 267(2):137-140

Swan GE, Carmelli D (2002) Impaired olfaction predicts cognitive decline in nondemented older adults. Neuroepidemiology 21(2):58-67. https://doi.org/10.1159/000048618

Thorvaldsson V, Macdonald SWS, Fratiglioni L, Winblad B, Kivipelto M, Laukka EJ et al (2011) Onset and rate of cognitive change before dementia diagnosis: findings from two Swedish population-based longitudinal studies. J Int Neuropsychol Soc (JINS) 17(1):154-162. https://doi.org/10.1017/S135561771 0001372

Tombaugh TN, McIntyre NJ (1992) The mini-mental state examination: a comprehensive review. J Am Geriatr Soc 40(9):922-935

Tsai J-C, Chen C-W, Chu H, Yang H-L, Chung M-H, Liao Y-M, Chou K-R (2016) Comparing the sensitivity, specificity, and predictive values of the montreal cognitive assessment and mini-mental state examination when screening people for mild cognitive impairment and dementia in chinese population. Arch Psychiatr Nurs 30(4):486-491. https://doi.org/10.1016/j.apnu.2016.01.015

Van Hoesen GW, Solodkin A (1994) Cellular and system neuroanatomical changes in Alzheimer's disease. Ann N Y Acad Sci 747:12-35

Vassilaki M, Christianson TJ, Mielke MM, Geda YE, Kremers WK, Machulda MM et al (2017) Neuroimaging biomarkers and impaired olfaction in cognitively normal individuals. Ann Neurol 81(6):871-882. https://doi.org/10.1002/ana.24960

Watabe-Rudolph M, Begus-Nahrmann Y, Lechel A, Rolyan H, Scheithauer M-O, Rettinger G et al (2011) Telomere shortening impairs regeneration of the olfactory epithelium in response to injury but not under homeostatic conditions. PLoS ONE 6(11):e27801. https://doi.org/10.1371/journal.pone.0027801

Welge-Lüssen A (2009) Ageing, neurodegeneration, and olfactory and gustatory loss. B-ENT 5(Suppl 13):129-132

Wilson RS, Arnold SE, Schneider JA, Tang Y, Bennett DA (2007) The relationship between cerebral Alzheimer's disease pathology and odour identification in old age. J Neurol Neurosurg Psychiatry 78(1):30-35. https://doi.org/10.1136/jnnp.2006.099721

Wolk DA, Dickerson BC, Alzheimer's Disease Neuroimaging Initiative (2010) Apolipoprotein E (APOE) genotype has dissociable effects on memory and attentional-executive network function in Alzheimer's disease. Proc Natl Acad Sci USA 107(22):10256-10261. https://doi.org/10.1073/pnas.1001412107

Zhou G, Lane G, Noto T, Arabkheradmand G, Gottfried JA, Schuele SU et al (2019) Human olfactory-auditory integration requires phase synchrony between sensory cortices. Nat Commun 10(1):1168. https://doi.org/10.1038/s41467-019-09091-3

Publisher's Note Springer Nature remains neutral with regard to jurisdictional claims in published maps and institutional affiliations. 